Review

\title{
Malaria control in Pakistan: new tools at hand but challenging epidemiological realities
}

Q. Kakar, $^{1}$ M. A. Khan ${ }^{2}$ and K. M. Bile

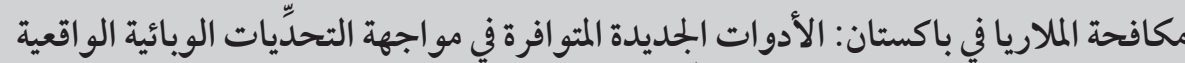

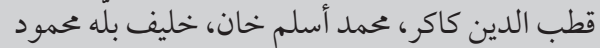

الخلاصـة: تتوطَّن الملاريا في باكستان وتُعد من الأولويات الصحية الوطنية. ويبدي الطفيلي والناقل له مقاومة تجاه الأدوية و المبيدات الحشرية الشائعة.

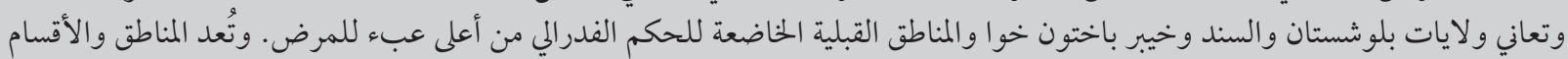

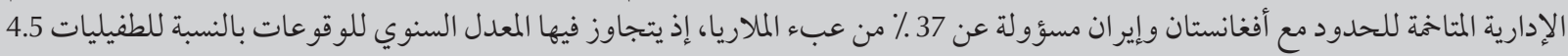

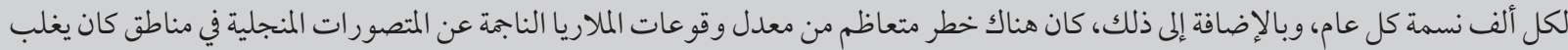

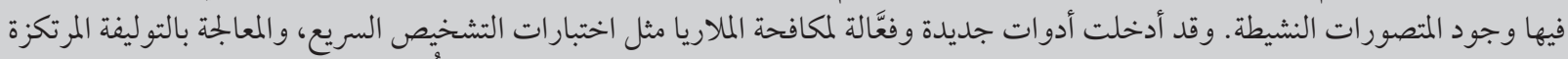

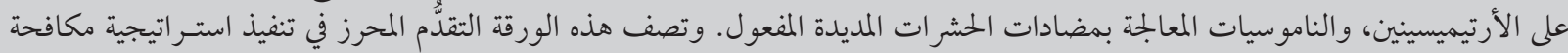

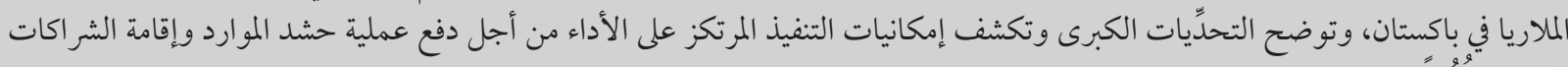

ABSTRACT Malaria is endemic in Pakistan and constitutes a national health priority However the parasite and vectors are showing resistance to common antimalarial drugs and insecticides. The provinces of Balochistan, Sindh and Khyber Pakhtunkhwa and the Federally Administered Tribal Areas have the highest malaria burden. Districts and agencies bordering Afghanistan and Islamic Republic of Iran account for 37\% of the malaria burden with an annual parasite incidence (API) exceeding 4.5/1000 population per year. Moreover, there has been a growing risk of Plasmodium falciparum malaria incidence in areas where previously $P$. vivax was predominant. New and effective control tools have been introducedsuch as rapid diagnostic tests, artemisinin-based combination therapy and long-lasting insecticide-treated nets. This paper reports the progress achieved in the implementation of a malaria control strategy in Pakistan, shares major outstanding challenges and unearths the potential of performance-based implementation for advancing resource mobilization and collaborative partnerships.

Lutte contre le paludisme au Pakistan : disponibilité de nouveaux outils et difficultés des réalités épidémiologiques

RÉSUMÉ Le paludisme, endémique au Pakistan, constitue une priorité sanitaire nationale. Cependant, les vecteurs et le parasite se montrent résistants aux insecticides et aux médicaments antipaludiques habituels. Les provinces du Baloutchistan, du Sindh et du Khyber Pakhtunkhwa, ainsi que les zones tribales sous administration fédérale sont les plus touchées par le paludisme. Les districts et agences à la frontière de l'Afghanistan et de la République islamique d'Iran participent à hauteur de $37 \%$ à la charge de morbidité du paludisme, avec une incidence parasitaire annuelle supérieure à 4,5/1000 chaque année. En outre, un risque croissant d'incidence du paludisme à Plasmodium falciparum dans des régions où auparavant prédominait le paludisme à $P$. vivax est apparu. De nouveaux outils de lutte efficaces ont été introduits, comme les tests diagnostiques rapides, les associations à base d'artémisinine et les moustiquaires imprégnées d'insecticide à longue durée d'action. Cet article fait état des progrès réalisés en matière de mise en œuvre de la stratégie de lutte antipaludique au Pakistan, expose les principaux défis et révèle le potentiel de mise en ouvre fondé sur les résultats afin de promouvoir la mobilisation des ressources et les partenariats de collaboration.

'World Health Organization, Country Office, Islamabad, Pakistan (Correspondence to Q. Kakar: kakarqut@pak.emro.who.int). ${ }^{2}$ National Malaria Control Programme, Islamabad, Pakistan. 


\section{Introduction}

Malaria is a mosquito-borne parasitic disease which takes almost one million lives per year and afflicts as many as half a billion people living in 109 countries in Africa, Asia and Latin America [1]. Malaria is predominantly a disease of poverty that is more prevalent in the rural areas, where the majority of the population often lives, resulting in substantial economic loss [2]. Pakistan is among the countries with a perceived growing risk of infection, in view of the extensive agricultural practices, vast irrigation network and monsoon rains in addition to sizeable population movements and a complex political situation in certain border areas that contribute to the country's malariogenic potential [3].

In Pakistan, malaria is the second mostfrequentclinicallysuspecteddisease entity after acute respiratory infection with 4.5 million probable cases reported from district health system public sector outpatient facilities in 2008. However, the estimated total number of malaria cases of 1.5 million cases per year is significantly smaller [4], which suggests a risk of erroneous treatment to about 3 million non-malaria cases. Moreover, the confirmed cases of malaria during the same period were only 104454, of which $70 \%$ were due to Plasmodium vivax and $30 \%$ to P. falciparum, these being the only two prevalent malaria parasite species in Pakistan [5].

The Directorate of Malaria Control in the Ministry of Health endorsed the World Health Organization's (WHO) Roll Back Malaria strategy in 2001 with the objective of halving the disease burden by 2010 and bringing the annual parasite incidence to $0.5 / 1000$ [6]. The programme is being implemented in endemic areas and will continue to the end of 2010 though the target seems difficult to achieve within this time. The proposed target to be attained has considerable bearing on maternal and child health and related Millennium Development Goals $[7,8]$. However, the paucity of comprehensive epidemiological and entomological information makes it difficult to generate reliable updates on the coverage and effectiveness of disease control interventions at the operational level [8]. This paper aims to report the progress achieved in the implementation of the Roll Back Malaria strategy in Pakistan, share major outstanding challenges and unearth the programmatic potential for implementation, resource mobilization and the building of collaborative partnerships.

\section{Methodology}

An in-depth analysis of available surveillance data within Pakistan's Malaria Control Programme and Health Management Information System was undertaken along with a Medline search for national and international reports on the malaria situation in Pakistan. National demographic and health surveys and field study reports were also reviewed, and major findings analysed.

\section{Results}

The prevalence and incidence of malaria in Pakistan varies from province to province and between districts within provinces. Figure 1 illustrates the results of a malariometric survey conducted in 19 highly endemic districts during 2009 using antibody-based rapid diagnostic tests. The districts' and agencies' results were aggregated by province and region and, show the highest parasite seroprevalence in the Federally Administered Tribal Areas (FATA), followed by Balochistan and Khyber Pakhtunkhwa (KPK), this being consistent with the programme-reported high annual malaria incidence from these areas.

Table 1 describes the overall annual parasite incidence (cases/1000 population), showing no evident reduction between 2004 and 2009, with a high annual parasite incidence being maintained both in Balochistan and the Federally Administered Tribal Areas as compared to other provinces, while Punjab maintained a very low annual parasite incidence of $<1$ case per 10000 population during that period. Similarly, for the same period, the proportion of falciparum malaria, out of the total confirmed cases, was highest in Sindh and Balochistan compared to other provinces and regions of the country.

The reported incidence of 2009 was higher in all provinces when compared to 2008 except in Sindh. In 2009 the highest slide positivity rate was recorded in the Federally Administered Tribal Areas, followed by Balochistan. The

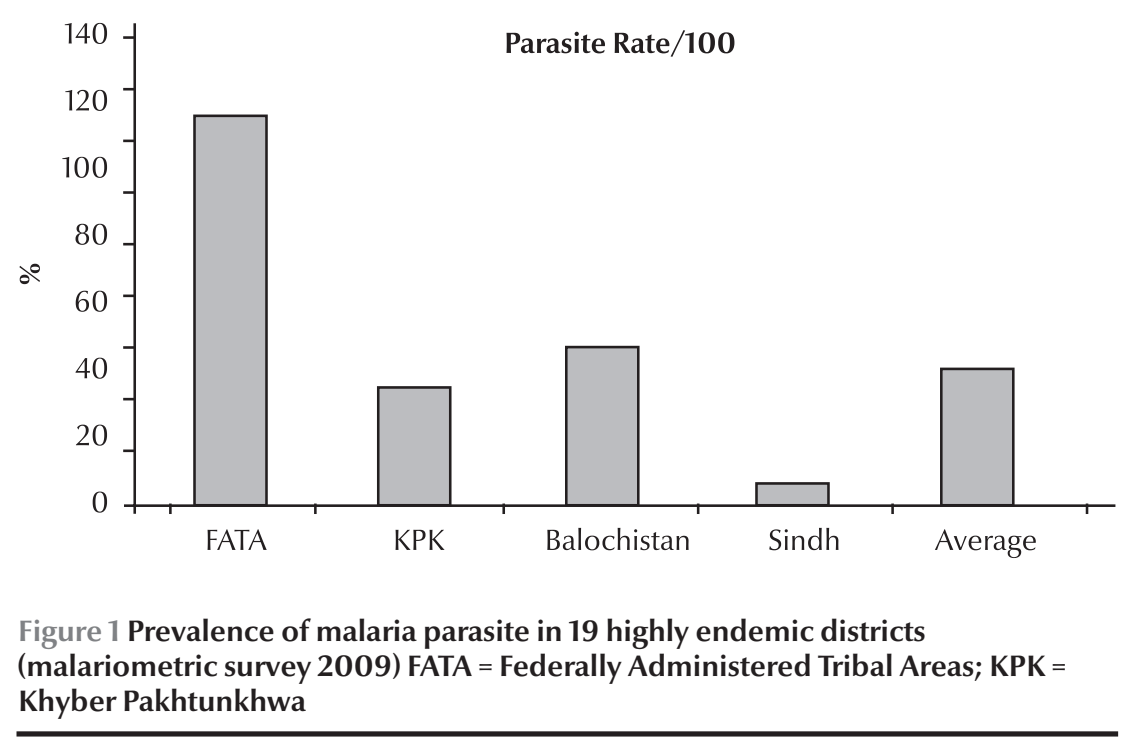




\begin{tabular}{|c|c|c|c|c|c|c|}
\hline \multirow[t]{2}{*}{ Area } & \multicolumn{6}{|c|}{ API - cases/1000 population/year (falciparum proportion) } \\
\hline & $\begin{array}{c}2004 \\
\text { API (\%) }\end{array}$ & $\begin{array}{c}2005 \\
\text { API (\%) }\end{array}$ & $\begin{array}{c}2006 \\
\text { API (\%) }\end{array}$ & $\begin{array}{c}2007 \\
\text { API (\%) }\end{array}$ & $\begin{array}{c}2008 \\
\text { API (\%) }\end{array}$ & $\begin{array}{c}2009 \\
\text { API (\%) }\end{array}$ \\
\hline FATA & $4.0(17.0)$ & $4.5(14.9)$ & $5.4(17.4)$ & $6.2(16.0)$ & $4.6(15.6)$ & $4.0(31.0)$ \\
\hline Balochistan & $4.2(34.0)$ & $7.4(44.3)$ & $6.2(33.9)$ & $6.3(43.0)$ & $4.6(27.0)$ & $5.8(32.0)$ \\
\hline KPK & $1.1(9.0)$ & $0.9(10.5)$ & $0.8(9.2)$ & $0.8(10.0)$ & $0.6(7.0)$ & $1.1(10.0)$ \\
\hline Sindh & $1.0(33.0)$ & $0.8(36.7)$ & $0.90(44.6)$ & $0.71(33.0)$ & $0.6(32.3)$ & $0.6(31.0)$ \\
\hline Punjab & $0.05(11.0)$ & $0.03(2.6)$ & $0.02(5.4)$ & $0.02(2.0)$ & $0.04(1.8)$ & $0.04(5.0)$ \\
\hline $\begin{array}{l}\text { Azad Jammu } \\
\text { Kashmir }\end{array}$ & $0.16(19.0)$ & $0.16(23.4)$ & $0.07(21.5)$ & $0.21(19.0)$ & $0.05(29.9)$ & 0.07 (13.0) \\
\hline Total & $1.7(20.9)$ & $2.3(22.0)$ & $2.2(21.8)$ & $2.4(21.8)$ & $1.8(21.0)$ & $1.9(19.0)$ \\
\hline
\end{tabular}

FATA = Federally Administered Tribal Areas; $K P K=$ Khyber Pakhtunkhwa.

proportion of confirmed cases reported from Punjab (low endemic area) was more in patients aged 15 years or more (82\%) and lowest among 5-10 year-olds (3\%), with higher rates among males (61\%) compared to females (39\%).

Table 2 shows the categorization of districts based annual parasite incidence during 2004-08, where all the highly endemic districts/agencies belonged to Balochistan and Sindh provinces and to the Federally Administered Tribal Areas, while all the districts of Punjab were clustered in the lowest endemicity rate category.

Studies conducted on the vector fauna of Pakistan showed that 24 different anopheles species have been reported from Pakistan including Anopheles culicifacies and An. stephensi, the vector species with known resistance to organochlorides (DDT, dieldrin), carbamates (propoxur) and organophosphates (malathion, fenitrothion) [9].

Table 3 describes the findings of the demographic and health survey of Pakistan 2006-07 regarding access to malaria preventive and curative services, which include possession and use of mosquito nets and access to treatment services among children with fever, depicting the low coverage of both long-lasting insecticide-treated nets and treatment services and highlighting the need for prompt and effective action. This survey was however conducted before the distribution of long-lasting insecticide-treated nets in 2008 attained through Global Fund support for 19 highly endemic districts.

The results of antimalarial drug efficacy monitoring surveys conducted in the country are presented in Table 4 . The cure rate with chloroquine treatment in 2004 was 58\% in Punjab and only $17 \%$ in Sindh and Balochistan. While the efficacy of sulfadoxine/pyrimethamine and amodiaquine in $\mathrm{Ba}$ lochistan resulted in a cure rate of $44 \%$ and $47 \%$ respectively, the cure rate with artesunate + sulfadoxine/pyrimethamine in the Federally Administered Tribal Areas in 2004 was 97\%. Likewise the tested efficacy of artesunate + sulfadoxine/pyrimethamine in Sindh, Balochistan and the Federally Administered Tribal Areas gave a cure rate of $100 \%$ in 2008. Similarly in 2009, the cure rate with artemether and lumefantrine in the Federally Administered Tribal Areas, Balochistan, Khyber Pakhtunkhwa and Sindh was also $100 \%$, although such studies need to be supported by independent quality control measures.

The national Roll Back Malaria strategic plan was first designed in 2001 and reviewed in 2007 to comprehensively account for the evolving malaria epidemiological situation, harness greater partnership for the programme and scale up operations to attain the Millennium Development Goal 6 as relevant to malaria. In this regard the following key strategic elements were pursued:

- promoting appropriate strategies and processes with enhanced monitoring and supervision

- extending and improving early diagnosis and rapid treatment services in all health facilities and applying these when appropriate in the community

- promoting insecticide treated materials, the targeted use of residual spraying and health education and introducing biological and environmental management approaches for integrated vector control

- improving preparedness, detection and response to epidemics

- developing viable in-country public-private partnerships as well as international partnerships to boost programme implementation

- commissioning health system research interventions to enhance free access to quality care and promote active community participation.

During its implementation process the programme made tangible efforts to enhance partnerships at national, provincial and district levels with national nongovernmental organizations as well as with international partners, facilitated by the receipt of grants from the Global Fund to fight AIDS, Tuberculosis and Malaria (Global Fund; rounds 2, 3 and 7 ) and through sustained WHO 


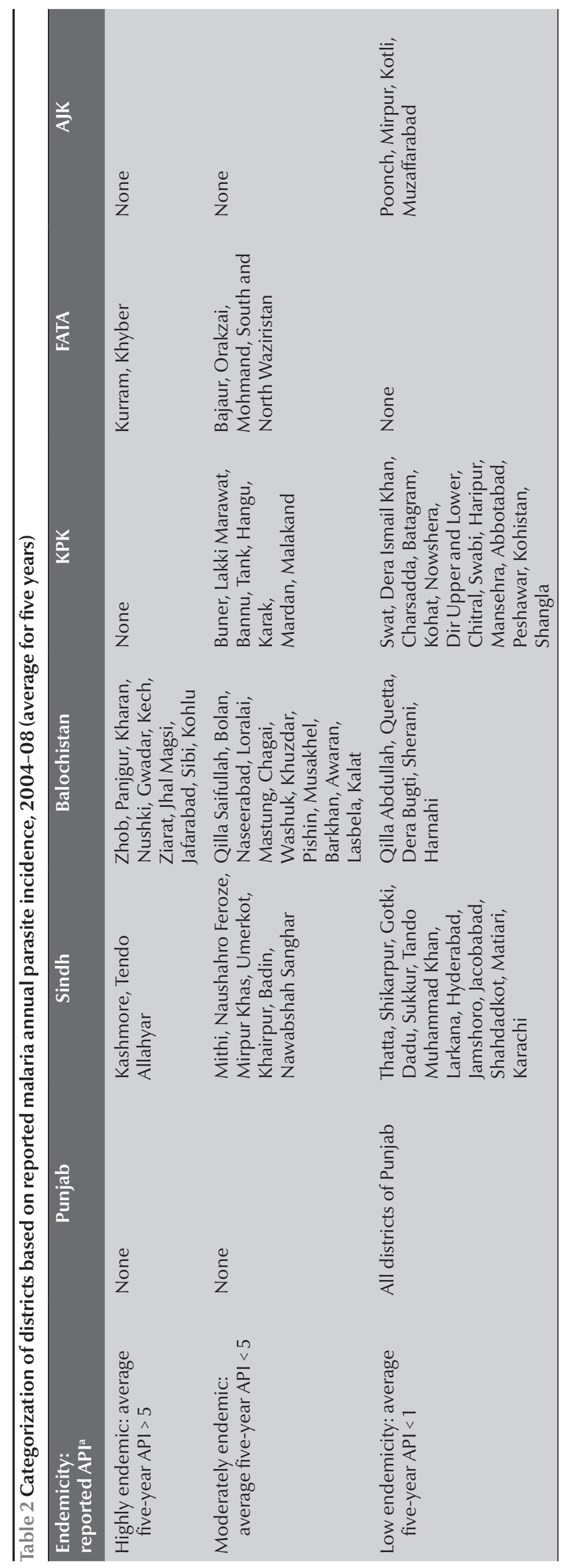

technical support. These partners included Health Net International, National Rural Support Programme, Association for Social Development, Mercy Corps, Merlin, WHO Basic Development Needs programme for community-centred interventions and Association for Community Development, all being engaged in Global Fund malaria grant projects as subrecipients. The Malaria Control Programme in Pakistan has also become an integral part of the United Nations (UN) "Delivering as One" initiative to generate synergy of action and prevent unnecessary duplication between different stakeholders. The Global Fund has been a major source for bridging the programmatic and financial gaps experienced by the programme, while WHO support has guided the implementation of the programme according to $\mathrm{WHO}$ standards (with required adaptation) through its headquarters, regional and country level professionals. Through its rounds 2, 3 and 7 of grants, the Global Fund provided US\$18 million to support malaria control interventions in targeted highly endemic districts.

\section{Discussion}

Malaria poses a major public health challenge in Pakistan and the country has been placed in the group of high burden countries of the WHO Eastern Mediterranean Region along with Somalia, Sudan, Yemen, Afghanistan and Djibouti, which collectively report more than $95 \%$ of the regional burden [10]. Malaria endemicity in Pakistan has been categorized on the basis of the average annual parasite incidence of the past five years. The majority of the districts falling in the highly endemic category were from Balochistan, the Federally Administered Tribal Areas and Sindh, with an annual parasite incidence as high as 5.5/1000 and 3.9/1000 in Balochistan and the Federally Administered Tribal Areas respectively, illustrating the 


\begin{tabular}{|c|c|c|c|}
\hline Variable/indicator & $\begin{array}{c}\text { Urban } \\
n(\%)\end{array}$ & $\begin{array}{l}\text { Rural } \\
n(\%)\end{array}$ & $\begin{array}{l}\text { Total } \\
n(\%)\end{array}$ \\
\hline Household possession of nets (treated or untreated) & $3159(3.5)$ & $6096(7.8)$ & $9255(6.3)$ \\
\hline $\begin{array}{l}\text { Households with at least one insecticide-treated } \\
\text { net (ITN) }\end{array}$ & $3159(0.7)$ & $6096(0.8)$ & $9255(0.8)$ \\
\hline $\begin{array}{l}\text { Children under } 5 \text { years who slept under a } \\
\text { mosquito net the night before the interview }\end{array}$ & $2636(1.2)$ & $6142(1.8)$ & $8778(1.6)$ \\
\hline $\begin{array}{l}\text { Children under } 5 \text { years who slept under an ITN the } \\
\text { night before the interview }\end{array}$ & $2636(0.2)$ & $6142(0.2)$ & $8778(0.2)$ \\
\hline $\begin{array}{l}\text { Pregnant women who slept under a mosquito net } \\
\text { the night before the interview }\end{array}$ & $364(0.7)$ & $829(2.0)$ & $1193(1.6)$ \\
\hline $\begin{array}{l}\text { Pregnant women who slept under an ITN the night } \\
\text { before the interview }\end{array}$ & $364(0.0)$ & $829(0.0)$ & $1193(0.0)$ \\
\hline $\begin{array}{l}\text { Children under } 5 \text { years with fever in the two weeks } \\
\text { preceding the survey who took antimalarial drugs }\end{array}$ & $791(2.5)$ & $1777(3.7)$ & $2569(3.3)$ \\
\hline $\begin{array}{l}\text { Children under } 5 \text { years with fever in the two weeks } \\
\text { preceding the survey who took antimalarial } \\
\text { drugs the same day/next day }\end{array}$ & $791(2.0)$ & $1777(2.8)$ & 2569 (2.6) \\
\hline
\end{tabular}

need for intensified and targeted control efforts in these regions.

All the districts of Punjab were ranked in the low endemic category with reported annual parasite incidence of $<0.1$ per 1000 population per year. The low endemicity in Punjab was reported to have resulted from reduced densities of Pakistan's primary vector An. culicifacies due to large-scale ecological changes in this province related to waterlogging and salinization, which favour the breeding of the salt-tolerant and less efficient vector A. Stephensi [11]. Moreover, the relatively better health infrastructure and socioeconomic status in the province may have contributed to this difference. Accordingly there has been a visible shift in the spatial pattern of malaria endemicity from the eastern agriculture plains to the north-western mountainous regions, particularly those bordering the Islamic Republic of Iran and Afghanistan, linked to a significant influx of refugees since 1980s [12]. Results of a malaria antibody seroprevalence survey conducted in 2009 during the non-transmission season in 19 highly endemic districts, showed a high prevalence rate in the
Federally Administered Tribal Areas (116 per 1000 population) followed by Balochistan (47.9 per 1000 population) [13], a rate many times higher than the reported yearly parasite incidence, corroborating the high transmission potential in these districts and the rising trend of malaria endemicity.

The demographic information of microscopically confirmed malaria cases is limited and scattered; however a situation analysis conducted in the low endemic province of Punjab in 2008 revealed that males of age $>14$ were more affected by malaria infections compared to females of the same age group indicating the low immunity linked with low endemicity and the relatively higher exposure potential of males to vector bites during their late-evening agriculture activities [14].

Information on severe and complicated malaria cases and mortality is not routinely collected by the programme or district health information system. However, the evolving initiative, in which the health information system will cover hospital inpatients, will fill this information gap and generate more comprehensive evidence on the morbidity and mortality burden of the disease.

P. falciparum and P. vivax are the only prevalent species of malaria parasite reported in the country; with P. vivax being the predominant species accounting for $>70 \%$ of the malaria burden in the country. The highest burden of vivax malaria was reported from Khyber Pakhtunkhwa and the Federally Administered Tribal Areas, illustrating the need for greater programmatic and health system strengthening in these regions [4]. Due to poor quality microscopy practices, mixed infections are rarely diagnosed and reported, as confirmed by a recent study carried out in the bordering regions of Afghanistan, Islamic Republic of Iran and Pakistan [15].

Studies conducted on the genetic characterization of Plasmodium vivax populations have shown multiplicity of infections, genetic diversity and allelic distribution of both the species [15]. Marked polymorphism of $P$. vivax populations indicated by the presence of extensive allelic variation has been linked to cross-border movement of populations living in border regions of 


\begin{tabular}{|c|c|c|c|c|}
\hline District & Province/area & Survey year & Drugs tested & Cure rate $(\%)$ \\
\hline \multirow[t]{3}{*}{ Khurram } & \multirow{3}{*}{$\begin{array}{c}\text { Federally Administered } \\
\text { Tribal Areas }\end{array}$} & 2004 & Sulfadoxine/pyrimethamine, artesunate & 97 \\
\hline & & 2008 & Artesunate+sulfadoxine/pyrimethamine & 100 \\
\hline & & 2009 & Artemether+lumefantrine & 100 \\
\hline Muzaffargar & Punjab & 2004 & Chloroquine & 58 \\
\hline Mirpur Khas & Sindh & 2004 & Chloroquine & 17 \\
\hline \multirow[t]{2}{*}{ Thatta } & Sindh & 2008 & Artesunate+sulfadoxine/pyrimethamine & 100 \\
\hline & & 2009 & Artemether+lumefantrine & 100 \\
\hline \multirow[t]{2}{*}{ Zhob } & Balochistan & 2008 & Artesunate+sulfadoxine/pyrimethamine & 100 \\
\hline & & 2009 & Artemether+lumefantrine & 100 \\
\hline \multirow[t]{5}{*}{ Kech (Turbat) } & Balochistan & 2004 & Amodiaquine & 47 \\
\hline & & & Sulfadoxine/pyrimethamine & 44 \\
\hline & & & Chloroquine & 17 \\
\hline & & 2008 & Artesunate+sulfadoxine/pyrimethamine & 100 \\
\hline & & 2009 & Artemether+lumefantrine & 100 \\
\hline
\end{tabular}

the country. The molecular characterization of P. falciparum field isolates in Pakistan revealed that a majority of patients having monoclonal infections had a genetic diversity and allelic distribution similar to those reported from India and other south-east Asian countries having low malaria endemicity [16].

Information on prevalent vectors and their bionomics demonstrate that 24 species of anopheles are known to occur in Pakistan with An. Culicifacies being the primary vector active in rural areas [9]. An. stephensi has also been incriminated in urban transmission; nevertheless, its role as a major vector needs further evaluation. Both vectors are endophilic in resting habits and usually bite from midnight till 2:30 a.m. The high density of these vectors during the post-monsoon period is linked to the seasonal peak of the disease. Of the five known sibling species of An. Culicifacies, $A$ and $B$ have been reported from the neighbouring countries of Islamic Republic of Iran, India, Afghanistan and China [17]; however, the lack of information on their role in malaria transmission requires further investigation.

Indoor residual spraying and longlasting insecticide-treated nets are currently the major tools of malaria control in the country. Theeffectiveness of indoor residual spraying depends on the efficacy of the insecticides used and the timing and quality of the campaign. In Pakistan resistance to previously used organochlorides (DDT, dieldrin), carbamates (propoxur) and organophosphates (malathion, fenitrothion) has been well documented [18]. The Malaria Control Programme has used pyrethroids for both indoor residual spraying and longlasting insecticide-treated nets since 1992, and the efficacy of this group of insecticides needs further validatation.

Resistance to the antimalarial drug chloroquine was first detected in 1981 in Sheikhupura district of Punjab. The consolidated analysis of nearly 20 years (1977-95) of susceptibility studies conducted in the former National Institute of Malaria Research and Training (NIMRT) in Lahore (closed in 1997), published in 1997, revealed a widespread R1 level chloroquine resistance (good initial response to the drug but parasitaemia reappears within one month of treatment) in Pakistan, with a frequency ranging from $30 \%$ to $84 \%$ [19]. Programme surveys on the efficacy of antimalarial drugs from 2004 to 2009 have corroborated that resistance to chloroquine is common in falciparum malaria in all parts of the country, while resistance to sulfadoxine/pyrimethamine has been on the rise. Moreover, artemisinin-based combination therapy has been found to be $100 \%$ effective in treating uncomplicated falciparum malaria cases; this is why artemisinin-based combination therapy was officially adopted as the first-line treatment for uncomplicated confirmed falciparum malaria. The absence of a external technical moderator for quality assurance in the survey was a limitation to be considered when conducting further surveys.

The Roll Back Malaria initiative was launched by WHO in 1998. Pakistan as a signatory to the Roll Back Malaria initiative commenced and has sustained its implementation since 2001. The plan was reviewed in 2007 to improve the national Roll Back Malaria strategic focus and recognize the existing epidemiological diversities in the country. The national strategic plan is being reviewed in 2010 and will be updated and is considering a two-pronged approach for malaria control in Pakistan: first, to pursue a universal coverage of early diagnosis, prompt effective treatment and multiple prevention interventions and secondly to eliminate the residual foci of malaria transmission in the low 
endemic province of Punjab through the launch of a pre-elimination strategy.

The efforts of the Malaria Control Programme to scale up distribution of long-lasting insecticide-treated nets in high endemic districts did not achieve the desired coverage, as revealed by the 2002 demographic and health survey of Pakistan, where the overall ownership of one long-lasting insecticide-treated net per household was only $0.8 \%$ and the overall net use by pregnant women and children less than five years of age was only $4.2 \%$ [20]. However, one million long-lasting insecticide-treated nets have since been distributed free of cost through the Global Fund round 7 grant in support of 19 target districts, while maintaining a high coverage of artemisinin-based combination therapy. This should result in a significant enhancement in the coverage of and access to these important interventions. Social marketing of long-lasting insecticidetreated nets using commercial channels may help improve the delivery of longlasting insecticide-treated nets to those at risk [21]. Pakistan is currently developing a proposal for the forthcoming Global Fund round 10 with the objective of mobilizing additional resources in order to consolidate the ongoing efforts for universal coverage towards achieving the defined Millennium Development Goal targets for malaria control.

Ever since the inception of the Roll Back Malaria project in Pakistan, the programme has passed significant milestones in partnership-building and development of policy guidelines for the new interventions of long-lasting insecticide-treated nets, rapid diagnostic tests and artemisinin-based combination therapy. The programme has also enabled the imposition of a ban on the production and sale of oral artemisinin monotherapies, injectable chloroquine and halofantrine, which had been injudiciously prescribed by care providers. The latter was a major success achieved through sustained joint collaboration between the government and WHO [22]. To further enhance programme capacity, the integrated vector management approach needs be adopted as national strategy, promoting also the control of other vector-borne diseases.

Malaria constitutes a major public health threat in the highly endemic districts and agencies of Pakistan, while the risk of impending epidemics in the low endemic regions of the country is looming. The government, the private sector, civil society organizations and development partners have to merge their efforts and work together to expand the available effective malaria control interventions for achieving the national Millennium Development Goal targets.

\section{References}

1. World Malaria Day, 25 April 2010. Countdown to save a million lives. Geneva, World Health Organization, 2010 [website] (http://www.rbm.who.int/worldmalariaday/background. html, accessed on 4 May 2010).

2. Mukhtar EM, ed. Economic analysis for a national study on malaria control in Pakistan. Islamabad, Pakistan, Malaria Control Programme, Ministry of Health, 2004.

3. World malaria report 2005. Geneva, World Health Organization, 2005.

4. Murtaza G et al. Malaria morbidity in Sindh and the plasmodium species distribution. Pakistan Journal of Medical Science, 2009, 25(4):646-649.

5. World malaria report 2009. Geneva, World Health Organization, 2009.

6. National strategic plan Directorate of Malaria Control 20062010. Islamabad, Pakistan, Malaria Control Programme, Ministry of Health, 2006.

7. Teklehaimanot $\mathrm{A}$ et al. Coming to grips with malaria in the new millennium. London, UN Millennium Project, 2005.

8. Bhatti MA et al. Malaria and pregnancy: the perspective in Pakistan. Journal of Pakistan Medical Association, 2007, 57(1):15-18.

9. Aslamkhan M. The mosquitoes of Pakistan: a checklist. Mosquito Systematics Newsletter, 1971, 3(4).

10. Huda A, Zamani G. The progress of Roll Back Malaria in the Eastern Mediterranean Region over the past decade. Eastern Mediterranean Health Journal, 2009, 14:S82-89.

11. Herrel N. et al. Adult anopheline ecology and malaria transmission in irrigated areas of south Punjab, Pakistan. Medical and Veterinary Entomology, 2004, 18:141-152.

12. Kazmi JH, Pandit K. Disease and dislocation: the impact of refugee movements on the geography of malaria in NWFP, Pakistan. Social Science \& Medicine, 2001, 52:1043-1055.
13. Malariometric survey 19 districts Pakistan (draft final report) 2009. Islamabad, SoSec Consulting Services, 2009.

14. Kondrachine A. Situation analysis of malaria in the province of Punjab 1-21st September 2008. Islamabad, Pakistan, Country Office, World Health Organization, 2008.

15. Zakeri $\mathrm{S}$ et al. Molecular characterization of Plasmodium vivax clinical isolates in Pakistan and Iran using pvmsp-1, pvmsp-3alpha and pvcsp genes as molecular markers. Parasitology International, 2010, 59(1):15-21.

16. Ghanchi NK et al. Genetic diversity among Plasmodium falciparum field isolates in Pakistan measured with PCR genotyping of the merozoite surface protein 1 and 2. Malaria Journal, 2010, 9:1.

17. Barik, TK, Sahu B, Swain V. A review on Anopheles culicifacies: from bionomics to control with special reference to Indian subcontinent. Acta Tropica, 2009, 109(2):87-97.

18. Rathor HR et al. Insecticide resistance in anopheline mosquitoes of Punjab province, Pakistan. Southeast Asian Journal of Tropical Medicine and Public Health, 1980 11(3):332-340.

19. Shah et al. Chloroquine resistance in Pakistan and the upsurge of falciparum malaria in Pakistan and Afghan refugee population. Annals of Tropical Medicine and Parasitology, 1997, 91(6):591-602.

20. Pakistan Demographic and Health Survey 2006-07: preliminary report. Islamabad, Pakistan, National Institute of Population Studies, 2007.

21. Qazi S, Sheikh BT. Social marketing of insecticide-treated bed nets: the case of Pakistan. Eastern Mediterranean Health Journal, 2007, 13(2):449-456.

22. Minutes of the 207th Meeting of the Central Licensing Board held on 20-21st July 2007. Islamabad, Pakistan, Ministry of Health, 2007. 